\title{
Multilingualism, Multilectalism and Register Variation in Linguistic Theory - Extending the Diasystematic Approach ${ }^{1}$
}

\author{
John Peterson
}

Although perhaps half of the world's population actively uses two or more languages in their daily lives, most formal linguistic theories are modeled on monolingual speakers of a single, invariant linguistic register. The present study attempts to rectify this by proposing a model of multilingual speech within the framework of Role and Reference Grammar (RRG). This model makes use of the "diasystematic" approach developed in Höder (2012) within a Construction Grammar framework, in which some "constructions" - ranging from lexical entries to abstract sentence patterns - are language-specific while others are unspecified for language, and extends this notion to include register variation, so that grammatical structures of all types are either specified or unspecified for both REGISTER and LANGUAGE. This allows us to capture the complex and multifarious interrelations between register variation and multilingualism, but also allows us to account for the many different types of multilingual speech.

\section{Introduction}

A large percentage of the world's population - more than half by some estimates - actively uses two or more languages in their daily lives, e.g., speaking

1 I wish to thank Utz Maas, Steffen Höder and an anonymous reviewer for their comments on earlier versions of this paper as well as the participants of the second Kiel RRG Workshop and the RRG conference in Freiburg, although I alone am responsible for any oversights and errors which the present study may contain. 
one language (the "Low" form, in Ferguson's 1959 terms) at home or with close friends and another in official or formal settings (the "High" form). Similar comments hold for speakers of "dialects" (Low), who are "multilectal" to the extent that they are also fluent in the standard language (High), which they use e.g. in more formal situations. A considerable amount of research shows that all of a multilingual speaker's languages are simultaneously "activated" whenever s/he speaks, even in cases where forms from only one language are encountered (e. g., Bialystok 2001: 114, Grosjean 1989). In multilingual speech this is even more apparent, as the speaker here makes use of elements from two or more languages within one and the same utterance or from one utterance to the next.

Despite these facts, most formal linguistic theories are either explicitly or at least implicitly modelled on monolingual language use, forcing us to view bilinguals as "two monolinguals in one person" (cf. Grosjean 1989), despite all evidence to the contrary. ${ }^{2}$ In fact, as many researchers point out (e.g., Gardner-Chloros 2009: 112-113), even most theoretical accounts of bilingual speech assume that the speaker is speaking EITHER one language or the other at any one moment, again despite considerable evidence to the contrary.

These problems are not restricted to bilingualism, however, since variation is also found in monolinguals, who regularly switch from one register to another in their daily routines, i. e., these speakers may be considered "multilectal" in this respect. Although this is often viewed as merely a matter of the appropriate choice of a particular lexeme or pronunciation, it can also involve other areas of grammar. Consider for example the Standard English sentence (1) with its more informal variant (2).

(1) She and I were going to go.

(2) Me 'n' her were gonna go.

In addition to any differences in pronunciation, alluded to here by spelling differences, it is clear that any rule to derive the appropriate form of the subject will have to be different for the two register variants, i. e. she and I in their so-called "nominative" forms vs. me ' $n$ ' her in their so-called "accusative" forms.

2 Following convention, in the following I will consistently speak of "bilinguals", although the following comments all hold as well for multilinguals who speak three or more languages. 
Although the colloquial form in (2) is considered substandard or even wrong by many speakers, it is nevertheless common in spontaneous informal speech and must therefore be accounted for in any full description of English. One possibility would be to make two separate descriptions, one for each of the two varieties, since in this case the two forms are generally not interchangeable: Where one is appropriate, the other typically is not. However, this is not a viable option, since a distinction between "informal" and "formal" - or perhaps "written" and "spoken" - is far too simplistic to account for the full range of register variation found in English (or any other language).

In my study, I will make use of the diasystematic approach developed in Höder (2012) within a Construction Grammar framework, in which some "constructions" - ranging from lexical entries to abstract sentence patterns - are languagespecific while others are unspecified for language. I will extend this notion to include register variation, so that grammatical structures of all types are either specified or unspecified for both REGISTER and LANGUAGE, working within the framework of Role and Reference Grammar (RRG). As the bilingual's languages fulfill many of the same functions as the monolingual's intralingual register variation, these two phenomena clearly interact with one another, yet as each of the bilingual's languages may also show a certain amount of intralingual register variation, register variation and choice of language must be viewed as separate phenomena.

Role and Reference Grammar or "RRG", the language theory which we will use in this study, is a typologically informed, monostratal theory of language. It has been chosen here for its flexibility and for the fact that it consciously avoids assuming "universal" categories for human language whose universality is questionable, e.g., grammatical relations such as "subject" and "object" or lexical classes such as "noun", "adjective" and "verb", 3 while at the same time providing a theoretical framework which can adequately account for the diversity found in human language. Furthermore, as noted in Van Valin (2005: 2), "RRG seeks to be more than a descriptive framework for the analysis of languages; it also strives to provide an explanatory framework for the analysis of language acquisition

3 For example, RRG can easily deal with languages such as Maltese (Neo-Arabic), in which grammatical relations such as "subject" and "object" are quite problematic (Peterson 2009), or languages such as Kharia (Munda, Austro-Asiatic), for which we have no evidence for the presence of nouns, verbs and adjectives (and considerable evidence against their presence) (Peterson 2011, 2013). 
and language processing." As we are ultimately interested here in a descriptively adequate account of the processes involved in bilingual speech as well as their acquisition by the bilingual learner, RRG would seem to be the natural choice for a theoretical account of this phenomenon as it allows us to capture all of these aspects in a unified manner.

Finally, the model developed here allows us to account for the many different types of bilingual speech, including those which contain a genuine "switch" from one language to another but also interference phenomena.

This study is structured as follows. ${ }^{4}$ Section 2 presents an overview of some of the different types of bilingual speech. As the present study cannot provide an exhaustive treatment of bilingual speech in general, this section provides a brief overview of what is traditionally referred to as "code-switching" or "code-mixing" as well as a very brief introduction to interference phenomena. Following this, section 3 presents an overview of the theoretical approach to (mono- and bilingual) speech assumed in the present study, which assumes the basic tenets of Role and Reference Grammar but which also draws heavily on the models proposed in Matras (2009) and Höder (2012), reinterpreting their discussions within the framework of RRG. In section 4 we then illustrate this model by applying it to a selection of the examples presented in section 2 for different language pairs, illustrating how structures from the two languages involved intertwine to form new structures. Section 5 then extends this analysis to intralingual variation. Here we will see that the same methods which apply to bilingual speech can also productively be applied to register variation. Finally, section 6 provides a summary of the present study and a brief outlook for future work.

\section{Multilingual speech}

The present section provides a brief overview of some of the different types of bilingual speech. We will restrict ourselves here to two very general headings: 1 . code-switching / code-mixing, and 2. "interference" in its broadest sense. As any attempt at exhaustiveness would greatly exceed the scope of the present study,

4 As an introduction to RRG is beyond the scope of the present study, every attempt has been made here to avoid theory-internal details and to keep the discussion as intuitive as possible, so that readers who are unfamiliar with RRG should nevertheless have few problems in following the discussion. 
the following discussion must necessarily remain schematic and cannot deal with many important issues in any detail, such as e. g. the distinction between loanwords and code-switching. ${ }^{5}$

\subsection{Functional bilingualism: code-switching / code-mixing ${ }^{6}$}

The terms "code-switching" and "code-mixing" - both as one word (with or without a hyphen) or as two words - are used differently by different researchers to refer to more-or-less different phenomena, such as whether or not the "switch" from one linguistic variety to another occurs inter- or intrasententially, or according to any number of other defining characteristics. The two terms will be used here interchangeably to refer to the more-or-less ad hoc use of elements from two linguistic varieties in one conversation, whether inter- or intrasententially.

The restriction to the more-or-less ad hoc use of elements from two linguistic varieties in the definition above refers to the fact that we exclude loanwords from this definition of code-switching / code-mixing. Although it is generally assumed that code-switching and borrowing are two distinct processes, it has proven enormously difficult, if not impossible, to maintain this distinction in practice. One solution, followed by Myers-Scotton (1993: 16), is to limit the occurrences of a particular linguistic form (i. e., a lexeme or word) to occurring in a maximum number of different conversations, in this case to fewer than three. As convenient as this may be, as Myers-Scotton herself acknowledges, this is a rather arbitrary choice. For these and other reasons, most other researchers have chosen alternative solutions to this issue, such as the composite "codeswitching-borrowing continuum" by Matras (2009), which acknowledges a number of relevant characteristics, such as "bilinguality", "composition", "functionality", etc. (cf. Matras 2009: 110-114 for further details). In the present discussion, we tacitly assume a continuum of this type but will not deal with this issue further here, for reasons of space.

5 There is a large number of excellent introductory works which deal with language contact in detail; two of the most recent works in this direction are Matras (2009) and Winford (2003).

6 While we will not assume here that bilingual speakers are necessarily conscious of the fact that they are using elements from two linguistic varieties in the same utterance (although this may be the case), we will assume that code-switching generally fulfills a function in discourse, e. g., highlighting information. In this sense, code-switching is much like intonation, which is "functional" as it conveys information, although the speaker him-/herself need not be aware of this fact. 
According to Muysken (2000), there are three basic types of code-mixing from a structural perspective: 1 . insertion, 2. alternation and 3. congruent lexicalization. ${ }^{7}$ These are illustrated in the following.

1. Insertion - As its name implies, this type of code-switching involves the "insertion of material (lexical items or entire constituents) from one language into a structure from the other language." (Muysken 2000: 3, emphasis in original) The following two examples from student presentations, both containing German-Russian switches, provide an example of this type of code-switching (German lexemes and words are given in their written form here, Russian elements have been transliterated).

\section{Russian-German:}

(3) koška ha-t

abgenommen!

cat PERF.AUX-3sg lose.weight.PTCP

'The cat has lost weight!'8

In (3) the so-called matrix or "main" language is arguably German and the embedded language (underlined here) is Russian. ${ }^{9}$ Arguments for viewing German as the matrix language include the typical V2-position of the finite auxiliary verb, hat 'has', and the sentence-final position of the perfect participle form of the lexical predicate, abgenommen 'lost weight', which together form the so-called "perfect" in German. Furthermore, the very fact that the auxiliary, a grammatical morpheme, is in German strengthens the assumption that German is the matrix language here. In this analysis, the Russian word koška 'cat' is inserted into this structure in the pre-verbal slot referred to in German linguistics as the Vorfeld 'prefield', which is mandatory in declarative V2-sentences and which allows for only one element.

7 In Muysken (2013: 713) a fourth type of code-switching is mentioned, "backflagging", in which "the principal or matrix language in the code-switched discourse is not the original community language, but the language some speakers have shifted towards as an L2, and this L2 is marked with flagging elements from the original community language" which speakers use "to signal their traditional ethnic identity even though they themselves may have shifted to a dominant non-ethnic language." However, as this does not represent a separate structural type, we will not deal with it further here.

8 Example courtesy of Valeria Biller.

9 Cf. however the discussion in section 4 below, where it will be argued that the underlying sentence structure in (3) (= example (10) in section 4) could be either Russian or German. 
However, even assuming that German here is unambiguously the matrix language, the example is perhaps not as simple as it appears to be at first sight: The Russian expression koška in (3) is, structurally speaking, not just the insertion of a single noun ( $k o s ̌ k a)$ into an otherwise German sentence but rather the entire noun phrase koška; as Russian does not have obligatory determiners such as definite articles, a Russian NP can consist of a simple N, as in (3), whereas German, like English, generally requires NPs in the singular to contain an obligatory determiner such as the definite article. In (3) this would be the feminine, singular, nominative form of the definite article, die, as the noun Katze 'cat' is feminine in German and is here the subject of the clause, which appears in the nominative in German. As (3) does not contain such a determiner, we conclude that the entire $\mathrm{NP}$ is Russian, not just the N.

A slightly more complex example is presented in (4).

Russian-German:

(4) Ja putz-a-l-a

heute $v$ Büro.

1sG clean-STV-PST-F.SG today in office

'I cleaned today in the office.' ${ }^{\text {' }}$

In one analysis, the matrix language here is Russian and the underlined elements are all insertions from German. The first insertion, putz- 'clean (v)', is at the lexical level, while the predicate is otherwise Russian and is marked for Russian inflectional and derivational categories (past tense, feminine, singular and stem vowel). The next two insertions are more reminiscent of the structure in (3): heute 'today' is here not only a lexeme and word, it is an entire adverbial phrase and with that an insertion at the syntactic level; Büro 'office', on the other hand, is slightly different - here we have the Russian preposition $v$ 'in', which requires an NP as its complement, so that Büro here is a full NP, not just an N. As in (3) this is best considered a Russian-language NP, as a German NP here would require the appropriate article; as this NP does not have a determiner, it is a Russian NP consisting of the German-language N Büro.

2. Alternation - In this type of code-switching, longer stretches from one language alternate with those from another language linearly. The following presents a simple example, in which the English-Spanish bilingual speaker begins an ut-

${ }^{10}$ Example courtesy of Xenia Dulghir. 
terance in English and then switches into Spanish, then English, then Spanish, but each switch contains extended monolingual stretches.

English-Spanish:

(5) Why make Carol sent-ar-se atras pa'que everybody has to move pa'que

se salga?

REFL go.out.SUBJ.3SG

'Why make Carol sit in the back so everybody has to move for her to get out?'

(Poplack 1981: 589; my gloss)

3. Finally, Muysken assumes a third type of bilingual speech which he refers to as "congruent lexicalization". This is particularly relevant in cases of highly similar language structures, such as with dialects or linguistic varieties which have been in close contact with one another for a long time, so that they share a large number of structures which may then be congruently lexicalized "from different lexical inventories into a shared grammatical structure." (Muysken 2000: 3). (6) presents an example of this type of switching.

Dutch-West Frisian

(6) En de partij dy't hy derby blaasde, (Frisian) En de partij die hij erbij blies (Dutch) and the part that he thereby blew

is net [foar herhaling vatbaar]. (Frisian) is niet voor herhaling vatbaar. (Dutch) is not for repetition handable 'And the song he sang then is not fit to be repeated.'

(Wolf 1995: 12, cited in Muysken 2000: 6)

Muysken (2000: 6) writes: "Here, Frisian foar 'for' is sufficiently similar to Dutch voor 'for' to be an ambiguous switchpoint; Dutch herhaling vatbaar is not a constituent, but two words that form an idiom together with voor."

These three types should be viewed as ideal types, so that code-switching between a particular language pair may be (and often is) best viewed as more-or-less insertional, more-or-less alternating and / or more-or-less of the congruent lexicalization type, depending on a number of factors, both structural and other (cf. 
the discussion in Muysken 2000), and membership to one or more types is not always entirely unambiguous. ${ }^{11}$

The inclusion of the preceding discussion of these three types here is simply to point out that code-switching strategies can and do vary considerably and can affect various linguistic levels, from phonology (although this is seldom encountered in the literature on code-switching) to the lexicon and morphosyntax. As such, any attempt to account for code-switching between any two languages must be able to account for all three types:

- Insertion and alternation appear to be the two most difficult to account for theoretically: With insertion, we have two grammars which combine directly within one and the same clause (or at least sentence), with some structures deriving from one language, some from another, but a number of constructions containing intertwined elements from both languages.

- In alternation, we at least tendentially have longer stretches of monolingual speech in one language followed by longer stretches in the other language. Nonetheless, here as well we can find examples in which two grammars combine to form a single clause; cf. e. g. (5), where the predicate of the first clause is make sentarse, with elements from English and Spanish.

- With congruent lexicalization, on the other hand, the two languages involved have essentially the same structure (at least within the unit under consideration) so that it is often not possible nor desirable to decide which language which structures derive from, other than perhaps at the lexical level. Nevertheless, any model for bilingual speech must also provide an adequate account of this form of code-mixing, and as we will argue in the following sections, the approach taken here will be to consider these structures neither one language nor the other but rather structures which are unspecified for language.

With respect to function, there is a considerable amount of literature dealing with the many "metaphorical" functions (Gumperz 1982) which have been attributed to code-switching / code-mixing, and no attempt will be made here to give an exhaustive account of these, as the present study is primarily concerned with structural issues. For an overview of literature on this topic, the reader is

${ }^{11}$ This claim is strengthened by the fact that Muysken (2013: 713) views (5) as typical for congruent lexicalization, whereas I view it as a typical example of alternation. In fact, arguments can be made for both analyses. 
referred to works such as Gardner-Chloros (2009), Gumperz (1982) and Winford (2003).

One of these "metaphorical" functions which has often been overlooked but which seems to be one of the major motivations behind code-switching is information structure: As Kaschubat (2004: 117-119) argues in her study of RussianGerman code-switching, ca. $90 \%$ of all cases of insertional code-switching in her corpus involving a single switched item occurred within the "rhematic" part of the sentence or, in RRG terms, within the actual focus domain, while virtually all of the remaining $10 \%$ are cases in which the German unit, within an otherwise Russian sentence, refers to an argument which has already been activated in the discourse. With that, this highlighting function of code-switching is clearly one of the primary functions of code-switching, and as we shall see in section 4, this is also easily captured within the framework of RRG.

\subsection{Non-functional switches: "interference" and "slips of the tongue"}

Generally speaking, there are two types of contact phenomena which can be considered non-functional in the sense that they do not fulfill any of the "metaphorical" functions discussed above in section 2.1. In the one type, we find utterances which contain at least some non-lexical structures from more than one language (e. g., word order), whereas the second type consists of lexical material stemming from the contextually "wrong" language. For ease of presentation, we discuss the two together in the following under the term "interference" and do not differentiate further between them.

We begin our discussion here with example (7), taken from Matras (2009: 73; gloss has been added here) and deriving from a seven-year-old German-English bilingual whose dominant language is English.

German (non-standard), influenced by English

(7) er ist gröss-er denn mir

3SG.M.NOM COP.NPST.3SG big-COMPAR 'than' 1SG.DAT

'he is taller/bigger than me'

As Matras notes, the non-standard use of denn mir in (7) in all likelihood derives from its similarity to the English form than me, whereas the standard German form would be als 'than' (in comparison) and ich '1sG.NOM': denn has most likely 
been selected due to its phonological similarity to English than as well as to a number of vague semantic similarities ${ }^{12}$ and the use of the dative form $\mathrm{mir}$ instead of the standard form ich (nominative) also derives in all probability from its phonological similarity to the oblique form of the English pronoun me (Matras 2009: 73-74).

Although interference has traditionally been viewed negatively, e. g., in studies dealing with L2 teaching, where interference (or "transfer") phenomena are viewed as mistakes stemming from L1, as Matras (2009: 74) argues, interference can be viewed more neutrally as a creative process in which a speaker makes full use of his or her entire linguistic repertoire in a context in which elements from just one subset, i. e., from the appropriate "language", would be expected.

The "transfer" of an abstract construction from one language to another can be due to any number of reasons, including the lack of proficiency in the "importing" language or the fact that the constructions in both languages are structurally quite similar, as in (7). However, even ignoring the cases in which this transfer is indeed due to the lack of proficiency in one of the two languages, such unintentional switches are nevertheless still quite common and are often due to influence from what Matras (2009) refers to as the pragmatically dominant language, which he defines as "the language that the speaker associates most closely at the moment of interaction with the routine implementation of communicative tasks that are similar to the ongoing task" (Matras 2009: 98). That is, the simple fact that the speaker has been speaking one language for some time and then switches to another language can be enough to trigger the presence of linguistic structure from the "wrong" or contextually inappropriate repertoire. This particularly affects what Matras (2009) refers to as the "monitoring-and-directing apparatus" and affects above all routine-like language activities such as semi-lexical speech-act markers (e. g., tags, affirmative signals, etc.) as well as connectivity and interaction operators (coordinating and subordinating conjunctions, sequential markers, fillers), among others (cf. e. g. Matras 2009: 98-99).

Cf. the following example, adapted from Maas (2008: 469), in which we find an extrasentential German interjection (underlined) at the beginning of an otherwise Finnish sentence:

${ }^{12}$ As Matras (2009: 73-74) notes, denn can in fact be used in formal and literary constructions as a marker of comparison, although he rightfully notes that this seven-year-old is unlikely to be familiar with this construciton. 
German-Finnish

(8) $\underline{\text { Ach }}$ on-k[o] su-ll kiire?

INTERJ COP.PRS.3SG-Q 2SG-ADESS (< sinu-lla) haste

'Oh, you're in a hurry?'

Although such "transferred" elements tend to be identifiable as language-specific elements, the monitoring-and-directing function which they fulfill appears to require considerable attention, so that these elements can "slip through" the context filter unnoticed. The case with abstract structures is somewhat different although these structures can also belong to one repertoire or the other, their respective membership is not as apparent as with lexical material, which tends to flag an utterance as belonging to a particular language in a way that the use of an abstract construction does not. Hence, the fact that the speaker is "mixing languages" may even go entirely unnoticed by the speaker him- or herself as well as by his or her interlocutor(s).

The following presents an example of such a structural "borrowing": Jarząbkowska (2012) contrasts Polish as it is spoken in Germany with that spoken in Poland. In her study, Jarząbkowska shows among other things that speakers of Polish in Germany overtly mention the subject NP altogether about twice as often as Polish speakers in Poland, although this varies considerably according to topic and genre. For example, two speakers of Polish living in Germany used four times as many personal pronouns in describing a picture of a market place as did a comparable speaker of Polish living in Poland (cf. Jarząbkowska 2012: 56).

This can be explained as follows: (Standard) Polish is a so-called "pro-drop" language in which the subject is marked on the verb and need not be overtly expressed by means of an independent NP; when an overt subject NP is present, this unit is typically focused. German, on the other hand, is not a "pro-drop" language, and with few exceptions (e. g., subject ellipsis in topic chains) all subjects must be mentioned overtly, despite the presence of subject marking on the verb. Consider now example (9). 
German-influenced Polish

(9) Jak pierwsz-y raz

$$
\text { by-t-a-m na urlopi-e,... }
$$

as first-NOM.SG.M once.NOM.SG.M COP-PST-F-1SG on vacation-LOC.SG.M

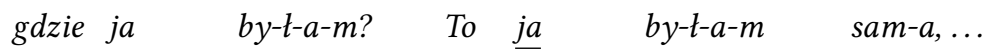

where 1sG.NOM COP-PST-F-1SG then 1sG.NOM COP-PST-F-1SG alone-NOM.SG.F

'When I was on vacation for the first time, ... where was I? I was alone then ...'

[Dan II: 4_50-4_51] ${ }^{13}$

At issue is the fact that the subject pronoun in the last clause, the underlined ja '1SG.NOM', is overtly present in (9), although it is generally only found with focus in the speech of native speakers living in Poland (cf. e. g. Bartnicka et al. 2004: 280-281, 499-501, Bielec 1998: 14-148). Although the presence of the 1st person, singular pronoun $j a$ in (9) may not qualify as "incorrect", for most speakers of Polish its use in (9) is nonetheless not typical, and its presence here is most likely due to the influence of German in the daily lives of these speakers. ${ }^{14}$

In a situation in which two or more languages are used in daily speech, it is likely that the structures of these languages will gradually converge to some extent, potentially resulting in convergence areas (Weinreich 1958: 379). ${ }^{15}$ There is now abundant research showing that such convergence areas can be found in all parts of the world. ${ }^{16}$ Given enough time and a high level of bilingualism (among other factors), the processes outlined above can lead to considerable convergence, so that even non-related languages which were once typologically very different can come to resemble one another quite closely.

In the following section, we present an overview of the model of (bilingual) speech which we assume here, which essentially follows that in Matras (2009).

${ }^{13}$ This example is taken from a corpus compiled by Jarząbkowska and myself and financed by the University of Kiel, whose support I gratefully acknowledge here.

${ }^{14}$ Similarly, cf. Johanson (2008: 73) on overmarking with respect to anaphora.

${ }^{15}$ Although the term Sprachbund or "language league" is undoubtedly more common, I follow Weinreich (1958: 379) in using the term "convergence area" to refer to such areas, as it is questionable whether languages can form any meaningful kind of "league" (or what this term could actually mean) and since what is at issue is to what extent the languages of a particular region have converged over the course of time.

${ }^{16}$ One example from my own research is Jharkhand in central-eastern India, in which languages of the Munda and Indo-Aryan families have come to share a number of traits due to their prolonged contact. Cf. Peterson (2010) for details. 
We will then adapt the diasystematic approach to bilingual speech, developed in Höder (2012) within the framework of Construction Grammar, to an RRG format and illustrate this with a number of examples in section 4 .

\section{The diasystematic approach}

In recent years, research into bilingual speech has increasingly been turning away from viewing languages as "discrete, identifiable and internally consistent wholes" (Gardner-Chloros 2009: 9) and towards viewing them as more permeable complex systems of rules, patterns, and / or constructions (cf. also e. g. Muysken 2000: $250-278){ }^{17}$ As such, many rules can be viewed as common to both languages, while other rules will of course be unique to one language or the other. These rules, both the language-specific as well as the unspecified ones, can refer to any structural level, such as clausal word order or prosody, or overt structures such as lexical morphemes (including their meanings), interjections and much more. This view is perhaps best summarized by the following quote, from Matras (2009: 4):

My principal assumption [...] is that bilingual (or multilingual) speakers have a complex repertoire of linguistic structures at their disposal. This repertoire is not organised in the form of 'languages' or 'language systems'; the latter is a metalinguistic construct and a label which speakers learn to apply to their patterns of linguistic behaviour as part of a process of linguistic socialisation. Rather, elements of the repertoire (word-forms, phonological rules, constructions, and so on) gradually become associated, through a process of linguistic socialisation, with a range of social activities, including factors such as sets of interlocutors, topics, and institutional settings. Mature multilingual speakers face a constant challenge to maintain control over their complex repertoire of forms and structures and to select those forms that are context-appropriate.

It is essentially this view which we also assume here, although we will freely speak of "languages" to refer to the patterns of linguistic behavior referred to in the quote above which speakers view as different linguistic systems (including "dialects"). ${ }^{18}$ That is, we follow other researchers in assuming that neither of the bilingual's languages is ever "turned off" simply because s/he at any one

\footnotetext{
${ }^{17}$ Although it is not always clear whether a description in terms of rules, patterns or constructions is most appropriate, in the following I will simply speak of "rules" for ease of discussion.

${ }^{18}$ We will, however, not speculate further here as to when bilingual speakers come to realize that they speak two separate "languages".
} 
particular moment is making exclusive use of forms which belong to only one of the two repertoires (i.e., "languages"). That is, the bilingual has at any given moment the option of using linguistic structures (in the broadest sense) from either repertoire for any number of reasons, such as the "metaphorical" uses referred to in section 2.1 .

In line with this view, it appears that linguistic structures - regardless of which language they belong to - are presumably first learned as general structures which are unmarked for context: "From the very beginning of the language acquisition process, the child-speaker learns that some linguistic items are 'universal', that is, they can be employed irrespective of setting or interlocutor. This principle of the existence of unique referents within the repertoire continues to accompany the bilingual speaker even in later states. Even the more mature communicator entertains the notion that certain items are exempt from the need to select among repertoire subsets." (Matras 2009: 39)

This is a gradual process in which the multilingual speaker presumably assumes that all structures are generally employable until evidence is encountered that a particular structure is restricted to one language or the other:

As the repertoire expands, so does the realisation that the use of word-forms (and later of constructions) is subject to situational and contextual constraints. Until such realisation is achieved, communication is a trial-and-error, experimental activity. The child tries to balance the benefits from exploiting the full repertoire for maximum effectiveness of expression against the need to maintain communicative harmony by complying with constraints on the appropriateness of the selection of word-forms and constructions. It is through this kind of prolonged process of linguistic socialisation that the repertoire is gradually shaped into subsets, or 'languages'. (Matras 2009: 68)

Figure 1, from Matras (2009: 5), summarizes this view of bilingualism schematically. In this model, the bilingual has a number of context-bound forms at his or her disposal. Like all speakers, the bilingual speaker wishes to be as fully expressive as possible, but unlike the monolingual speaker, s/he can choose from a number of constructions from different languages, some of which s/he may consider better suited for a particular purpose than others. However, bilingual speakers are not entirely free to choose from their full linguistic repertoire - successful communication crucially depends upon the interlocutor's ability to understand a particular linguistic structure. Hence, the interplay between the context-bound selection of forms and the full exploitation of the resources at one's disposal is 
regulated by the need to maximally reduce the number of communicatory hurdles in successful communication.

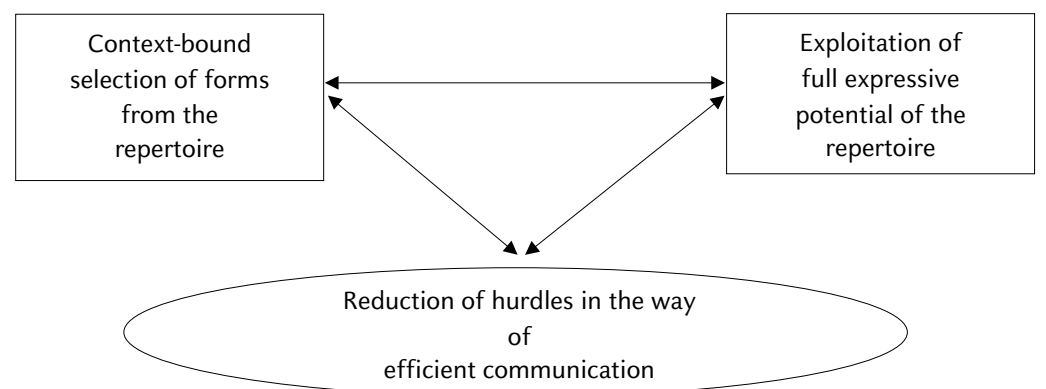

Figure 1: The interplay of factors in communication in language contact situations (Matras 2009: 5)

In such a model not only are both languages necessarily "switched on" during communication, it must also be assumed that the speaker (and in the case of effective multilingual communication also the interloctur(s)) at all times have direct access to all levels of linguistic structure and the corresponding meanings from both or all repertoires, from prosody and segmental phonology, the lexicon, morphosyntax, information structure and also "monitoring-and-directing" structures such as tag questions, etc. But equally importantly, this model adequately takes into account the context-bound nature of linguistic structures, whether from different languages, dialects or registers, as the difference between "languages" and "dialects" is one of degree (cf. Matras 2009: 99). We will return to this point in section 5 .

In a recent study on bilingualism within a Constructive Grammar approach, Höder (2012) develops what he refers to as the "Diasystematic Construction Grammar (DCxG)" model to account for bilingual structures, especially within closely related languages and dialects. This model, which has much in common with the basic assumptions on bilingualism outlined above, is based on the notion of "diasystem" developed by Weinreich (1954) to account for structures which are shared between two linguistic varieties.

As Höder (2012: 245) notes, the basic process in establishing a diasystem is that of "interlingual identification" (Weinreich 1953: 7-8), in which components in two different linguistic systems are essentially viewed as equivalent due to 
perceived similarities. ${ }^{19}$ However, it must be emphasized that the determination of such "equivalents" is not entirely a straightforward matter, as what is at issue are not so much verifiable equivalents but rather equivalents which the speakers themselves view as such (cf. Höder: 2012: 245). This complex system of perceived differences and similarities between the two (or more) linguistic systems plays a central role in organizing the speech of multilinguals, and the more closely related two varieties are (from a purely structural perspective), the more highly developed their diasystematicity will be.

Diasystematic links and dia-elements constitute a network through which two language systems used within a multilingual speaker group are interconnected. The degree to which two varieties in contact participate in the common diasystem depends, of course, on their typological similarity: closely related and typologically similar languages can more easily develop a high degree of diasystematicity - i. e. the common intersection of their systems is larger - than more distant languages, which retain a larger proportion of idiosyncrasies in their systems ... (Höder 2012: 246)

As already noted, this extension of Weinreich's notion of diasystematicity fits in well with the model of multilingualism outlined above from Matras (2009), hence Höder's (2012) model can serve as our point of departure for a theoretical approach to bilingual speech within RRG. The model we assume here is summarized in Figure 2, where two languages, L1 and L2, both possess a number of structures which are unique to these two languages, although a number of structures are also shared by both. As just noted, the number of common linguistic structures will depend upon the typological similarity of the two (or more) languages involved.

"Structures" here refers to elements from all levels of grammar, both concrete forms and abstract rules and patterns. This thus includes, among others, morphs and morphemes (grammatical and contentive), logical structures from the lexicon, syntactic templates, potential and actual focus domains, case-assigning rules, constructional schemas ${ }^{20}$ (or parts thereof), etc.

${ }^{19}$ Although Weinreich was primarily concerned with the relationships between dialects in his writings, the notion of interlingual identification, like that of diasystem, can easily be extended to other types of linguistic varieties.

${ }^{20}$ Constructional schemas in RRG bring together various areas of the grammar involved in a particular construction, including syntax, morphology, semantics and pragmatics. For reasons of space, we will only refer to these very generally in the following discussion. Cf. Van Valin (2005: 131-135) for further discussion. 


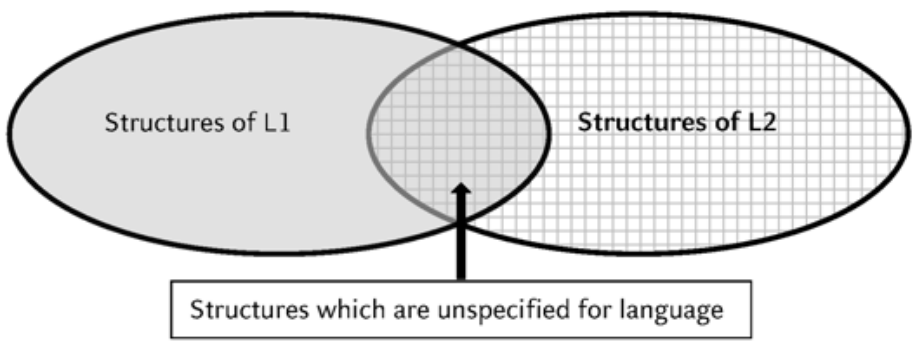

Figure 2: A schematic representation of bilingual linguistic structures

As RRG essentially views "languages" as networks of structures from the areas just mentioned, as well as rules for linking one level with another (e. g. semantics and syntax), the theory is well equipped to handle bilingual speech as this is understood here - both languages are viewed as networks of context-bound structures, to both of which the speaker and interlocutor have access and from both of which the speaker may freely combine structures to the extent that these are viewed as "interlingual equivalents" by speakers. This in turn can only be ascertained by a detailed analysis of the data, not by any pre-conceived notion of equivalence. Thus, the only real novelty to RRG proposed here is that these two networks are not viewed as completely discrete but rather as "permeable" or "penetrable", as they allow the inclusion of structures from other repertoires, to the extent that these are felt by speakers to "fit".

In the following section, this approach will be outlined in more detail and illustrated by applying it to a number of the examples from section 2 . In section 5 , we will then expand this model to include intralingual register differences.

\section{Applying the model}

In the view of language assumed here, not only are both languages activated during bilingual speech, we have also argued that these languages are not to be viewed as discrete systems but rather as repertoires of linguistic structures bound together by convention, and that the bilingual in the course of his or her socialization learns to view these networks of structures as different languages. This essentially means that, in a formal language theory such as RRG, all information - including the form of a lexeme, its logical structure (i. e., "definition"), the language's syntactic inventory, information structure, etc. - can be indexed for 
the respective sub-repertoire to which it belongs, and that some structures will be unique to L1, others to L2, while others will be unspecified, as they are common to both L1 and L2. Furthermore, the individual structures of both repertoires may be combined with elements from the other repertoire to the extent that speakers view them as equivalent.

In this section, we illustrate this model by applying the principles from section 3 to a number of the examples of bilingual speech from section 2, concentrating on cases in which the two languages intertwine within the sentence or clause, such as insertional code-switching and interference. Let us begin with example (3), repeated here as (10).

Russian-German:

(10) koška ha-t

abgenommen!

cat PERF.AUX-3sG lose.weight.PTCP

'The cat has lost weight!'

At first glance, this would appear to be a simple case of insertion, in which a Russian referential phrase or "RP" ( $\mathrm{RP}_{\mathrm{RUS}}$, realized here by an $\left.\mathrm{NP}_{\mathrm{RUS}}\right), k o s ̌ k a$, has been inserted into a German core $\left(\mathrm{CORE}_{\mathrm{GER}}\right)$. In this interpretation, the structure RPRUS has been "interlingually identified" or equated with an $\mathrm{RP}_{\mathrm{GER}}$. We will abbreviate interlingual identification here through the sign “””, so that the interlingual identification of a Russian and German RP can be abbreviated as $\mathrm{RP}_{\mathrm{RUS} \equiv \mathrm{GER}}$. This is illustrated in (11). ${ }^{21}$

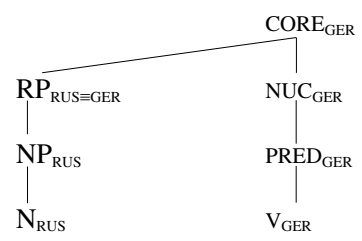

However, the overall structure of the core in (11) could also be Russian, since Russian also possesses a syntactic template for a cORE consisting of an RP followed by NUC in an intransitive CORE in sentence-focus structures (Rodionova 2001: 13-14; $25 ; 47)$, as in (10), which is an example of sentence focus. Hence, considering this

${ }^{21}$ I follow Ruhnau (2011) here in not assuming the presence of an obligatory precore slot (PrCS) in German. 
particular structure to be either Russian or German is at best an arbitrary decision. As such, we consider it better to view it as neither Russian nor German but rather simply as a core structure underspecified for language for the German-Russian bilingual: Although the clause-initial NP is Russian and the overt form of the predicate and the operators are from German (although the categories expressed by the operators are found in both Russian and German), the overall syntactic structure of the CORE, i. e., the syntactic template, is unspecified for language. We can illustrate this in a simplified manner as in (12), where elements which do not have a subscript are considered to be common to both languages.

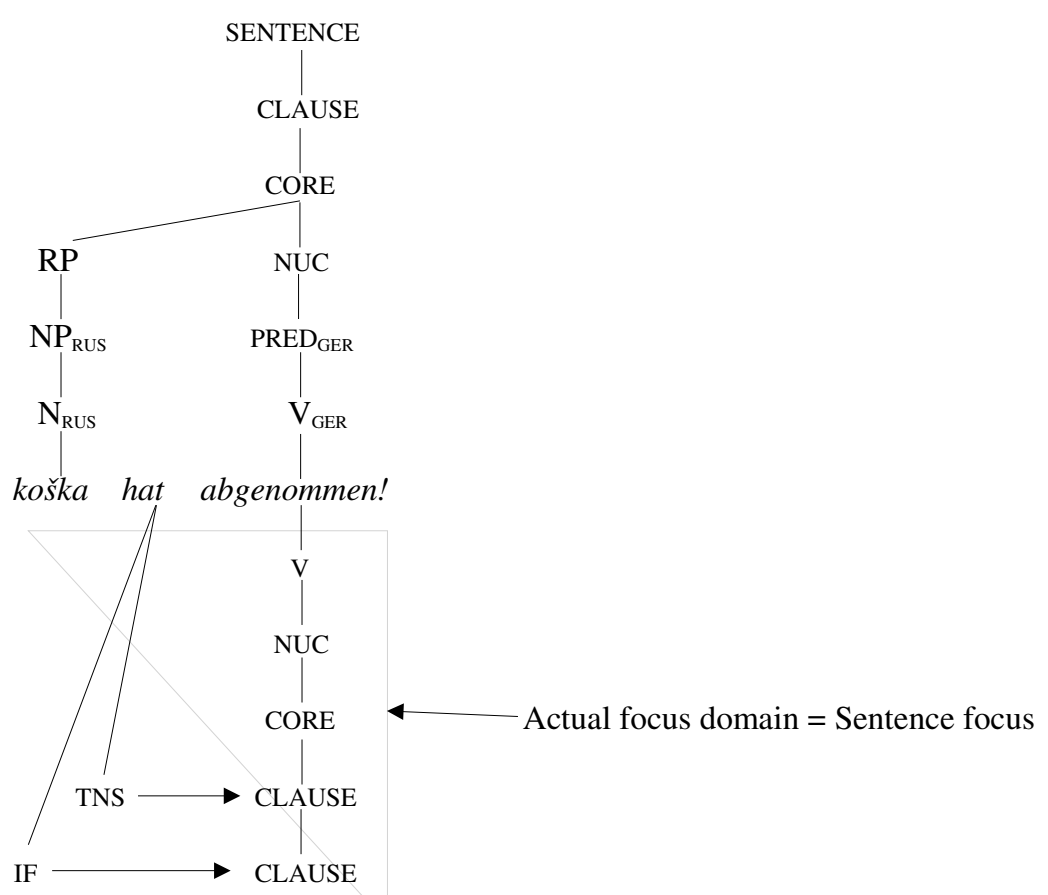

Logical Structure: $\left\langle_{\mathrm{IF}} \mathrm{DEC}\left\langle\left\langle_{\mathrm{TNS}} \operatorname{PST}\left\langle\text { do' }\left(k o s ̌ k a_{\mathrm{RUS}}\left[\text { lose.weight' }\left(k o s ̌ k a_{\mathrm{RUS}}\right)\right]\right)\right\rangle_{\mathrm{GER}}\right\rangle\right\rangle\right.$

The lack of an index in (12) does not have the same meaning as interlingual identification denoted by the sign " $\equiv$ ": Although much work must still be done here, intuitively at least there is a difference between those structures belonging to the area of overlap in Figure 2 (usually at an abstract level, such as word order or identity of the operators) which are structurally identical in both linguistic 
systems, such as SENTENCE, CLAUSE, CORE, RP and NUC in (12) (as well as the two operators indicated there), and those structures which differ from one another in both languages, from a strictly structural-linguistic perspective, but which are (more-or-less spontaneously) ${ }^{22}$ equated by the bilingual speaker during discourse, i. e., which have been interlingually identified. Although it may prove to be unfeasible to maintain this distinction in the long-run, it seems advisable at least for now to maintain this distinction wherever possible.

It should be stressed here that elements from both systems can be "inserted" into both systems at all levels of grammatical description. This includes both Johanson's (2008: 64) "selective copying", where "only individual selected properties - material, semantic, combinational and frequential properties" are "copied" (in his terminology) from one language into another, as well as "global copying", in which elements are copied "as a whole, including their material shape (substance) and properties of meaning, combinability and frequency." Furthermore, speakers can freely alternate within one and the same utterance / sentence between the two repertoires; cf. once again (4), where the speaker switches back and forth between German and Russian three times. Thus (4) is structurally similar to (10) - the main difference is that most overt material in (4) stems from Russian, as opposed to (10), where most overt material stems from German.

Thus, the present approach does not force us to decide arbitrarily which language a particular structure belongs to when its surface structure is ambiguous, as with the units SENTENCE, CLAUSE, CORE, RP and NUC in (12). As the research on code-switching abounds in ambiguous structures, an approach such as the present one is to be preferred over one which requires all structures to exclusively derive either from one language or the other. ${ }^{23}$ At the same time, it allows us to index structures which unambiguously belong to a particular language as well as those which have been interlingually identified as equivalent. Through this descriptive precision, the present modified version of RRG can eventually help us come to a better understanding of the processes involved in bilingual

${ }^{22}$ Note that Höder (2012: 245) emphasizes the conventionalized nature of such interlingual identifications more than I do, although he also recognizes that "interlingual equivalence is to some degree arbitrary and always reflects a creative act of a multilingual community", whereas I do not differentiate in principle between spontaneous and conventionalized equivalents nor any intervening degrees thereof. This issue requires further discussion, which is however beyond the scope of the present study.

${ }^{23}$ Compare this, e. g., with the often quite complex attempt to determine the identity of the matrix language in Myers-Scotton (1993: 66-74; 2002: 59-69). 
speech, such as identifying the structural properties ${ }^{24}$ which can trigger interlingual identification or "switches" from one repertoire to another.

Note that the approach taken here, along with its Construction Grammar precursor (Höder, 2012), essentially reverses the usual approach to the question of what linguistic units may or may not be "switched"; in stark contrast to many other theoretical approaches which aim to determine a priori which structures may derive from which language in which language pair, the present model is decidedly descriptive in its approach. This is not to say that this approach will not eventually be capable of predicting which elements may or may not be "switched" in a particular language pair, however, for the moment we are primarily interested in a descriptively adequate theoretical account of actual cases of bilingual speech, which the present model provides.

The present approach is not restricted to code-switching but may be applied to any bilingual language activity, including interference of the type found in (8), repeated here as (13) (from Maas 2008: 469).

German-Finnish

$$
\begin{aligned}
& \text { Ach on-k[o] su-ll kiire? } \\
& \text { INTERJ COP.PRS.3SG-Q 2SG-ADESS(<sinu-lla) haste } \\
& \text { 'Oh, you're in a hurry?' }
\end{aligned}
$$

(13) provides an especially simple example of bilingual interference: We have a SENTENCE structure, unmarked for language (for this speaker), consisting of a leftdetached position (LDP) containing a German interjection, ach, and preceding a monolingual Finnish CLAUSE. Whatever may have motivated this interference (cf., e. g., the discussion of the monitoring-and-directing apparatus in section 2), the approach taken here allows us to capture the structural facts easily without forcing a prefabricated analysis on the data. Similar comments hold for (7), repeated here as (14) (adapted from Matras 2009: 73).

\footnotetext{
${ }^{24}$ As Gardner-Chloros (2009: 7-9) points out, code-switching can and should be studied in a holistic manner. Due to the nature of this study however, we concentrate here on structural and lexical properties of bilingual speech, although the present approach should eventually also prove capable of dealing with other aspects of bilingual speech as well.
} 
German (non-standard), influenced by English
ist
größ-er
denn mir
3SG.M.NOM COP.NPST.3SG tall-COMPAR 'than' 1sG.DAT
'he is taller/bigger than me'

English and German share a similar structure for marking comparatives, namely (in the written language) ADJECTIVE-er + MARKER + STANDARD, i. e., an adjective marked (in regular cases) by the suffix -er followed by a marker - English than, German als - which precedes the standard of comparison, which appears in the oblique (or "accusative") case with pronouns in colloquial English, whereas in German this appears in the same case as the unit with which it is being compared; in the case of (14) this would be the nominative singular form ich. Thus, while the realization of the individual morphemes is different, the overall structure is the same for the two languages.

In (14) we find this general overall structure realized by morphs from German. However, the example is not Standard German - the form denn is indeed a German word, but one which is not normally used in this construction. As noted in section 2 (following the argumentation in Matras 2009: 73-74), denn in (14) is a case of interference presumably motivated by the fact that its form is similar to the English form than. Similarly, mir is a German word but its use here is not standard - the Standard German form would be ich. The use of mir in (14) is motivated by the fact that it sounds similar to English me, which may not be "correct" English (in a prescriptive sense, where I would be required) but which is certainly standard colloquial English.

Summarizing, the German forms denn and mir in (14) are in effect "not German" but rather English, but the speaker here has identified the two German words which are closest, phonologically speaking, to English than me, i. e., denn mir, as being equivalent with their English counterparts, presumably in an attempt to realize the entire utterance in German. Thus in (14) we have in effect the lexical entries for English than and me but realized by their closest German counterparts, phonologically speaking. In other words, the morphemes are English but the actual morphs are German, as the German morphs have been identified with the English morphs, which are bound to the English morphemes. This is reminiscent of "relexification", in which the overt form of a lexical entry derives 
from one language while the logical structure of this entry (i. e., its "definition") derives from another, which is easily accounted for in the present model. ${ }^{25}$

The present model also adequately captures cases of interference between two languages such as "borrowings" at the syntactic level. Consider example (9), repeated here as (15).

German-influenced Polish
Jak pierwsz-y raz
$b y-t-a-m$
na urlopi-e,...
as first-NOM.SG.M once.NOM.SG.M COP-PST-1SG-F on vacation-LOC.SG.M

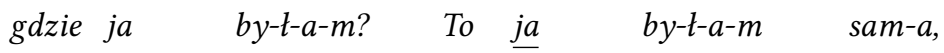
where 1sG.NOM COP-PST-1SG-F then 1sG.NOM COP-PST-F-1SG alone-NOM.SG.F 'When I was on vacation for the first time, ... where was I? I was alone then ..'

[Dan II: 4_50-4_51]

As was noted above, (15) is interesting as the overt subject pronoun in the last clause, $j a$ '1sG.NOM', is used here, although an overt subject is generally only found in standard monolingual speech when it is in focus. As the subject pronoun is not focused in (15) - rather, sama 'alone' is focused - its presence is presumably due to contact with German, as (15) stems from a speaker of Polish living in Germany. For ease of presentation, in the following discussion of this example we focus our attention only on the structure of the last CLAUSE.

Assuming that the subject pronoun is only overt when focused, this yields the two possible structures for (standard, monolingual) Polish in (16) and (17) which are relevant for the structure in (15). In (16) we find the subject expressed directly on the predicate itself, whereas in (17) it is expressed by a separate pronoun, provided that this pronoun is the "actual focus domain". ${ }^{26}$

\footnotetext{
${ }^{25}$ For a brief overview of relexification and its role in contact linguistics, cf. the entries for "relexification" in the index in Winford (2003: 409).

${ }^{26}$ This is in line with the discussion in Van Valin (2005: 18-19) for Latin, Polish and Croatian. As Polish is predominantly dependent marking, with RPs marked for case, when the "subject RP" is present, it is considered the subject of the clause. When however the "subject RP" is omitted, the subject marking on the verb itself is viewed as the subject of the core. The presence of the actual focus domain in (17) is to indicate that this structure is only licensed when the RP is (part of) the actual focus domain. While a constructional schema would arguably be a better means of representing this information, for ease of presentation we will not introduce the use of constructional schemas here, as the representation in (17) is most likely intuitively easier to understand without prior knowledge of RRG.
} 


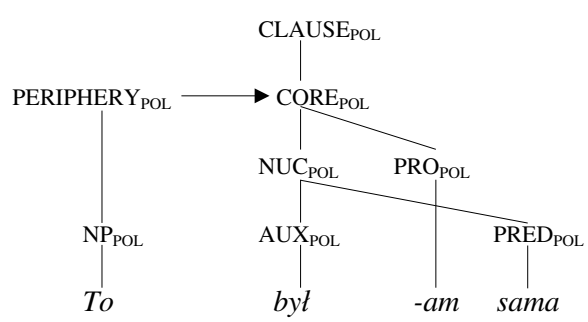

(17)

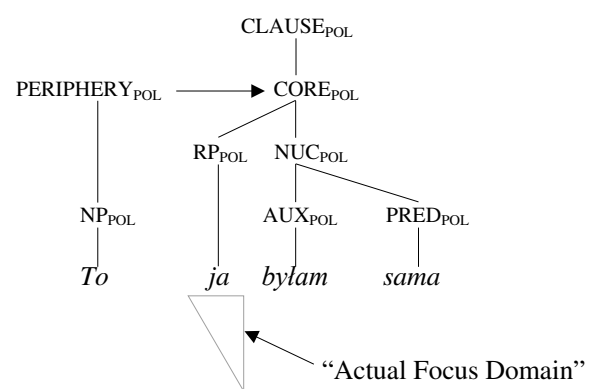

In German, on the other hand, the subject RP must always be overtly mentioned, even when its marking on the predicate is unambiguous. This is illustrated by the syntactic template in (18) for the German equivalent (slightly simplified).

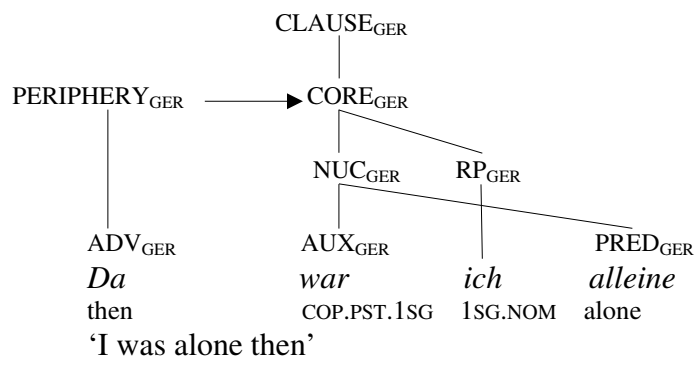

The Polish template in (17) with an overt subject pronoun is only licensed when the pronoun is in the actual focus domain, which however is not the case in (15). On the other hand, the German structure in (18) would seem to account for this, but note that word order with respect to finite verbs is quite rigid in German, so that the structure in (18), which requires an overt subject RP, is still not adequate to account for (15), although it is arguably the German requirement 
that subject RPs be explicit which is motivating the presence of $j a$ in (15), although the order of the elements is decidedly Polish. Hence, the resulting core structure is at the same time neither Polish nor German, but yet it is both: Here, the speaker has interlingually identified two possible structures with one another, neither of which would be prescriptively acceptable in either language in the present context. The result is a structure which is otherwise restricted in standard Polish to focused subjects, but this restriction has been relaxed here due to German influence. This is illustrated in (19), where the sign " $\bowtie$ ", 27 "natural join”, has been borrowed from relational algebra (with a somewhat different meaning here) to indicate a structure which has been interlingually identified in both languages but which is not found in exactly this form and function in either of the two languages involved.

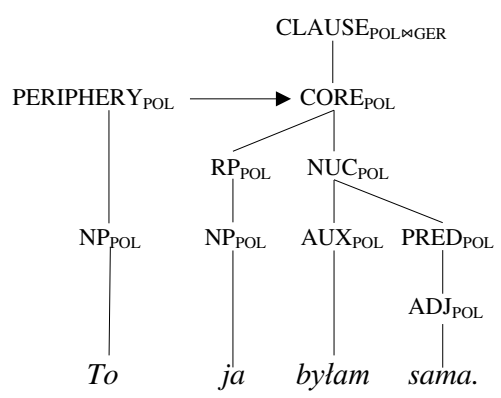

Natural join, or “ $\bowtie$ ”, presently has no theoretical value and is simply a convenient means of denoting a unit in the syntactic structure whose interlingual structure cannot easily be shown by syntactic trees alone. For example, in order to fully describe (19) we would need a constructional schema for pronominalization which would essentially be unspecified for German or Polish, and the Polish constraint requiring that this element be in focus would be replaced by the value "unspecified" for the corresponding pragmatic criterium in the German constructional schema.

According to the data in Jarząbkowska (2012), many Polish speakers in Germany regularly use the combined German $\bowtie$ Polish structure in (19) when speaking Polish. As such, we are no longer dealing with "interference" with these speakers except from a historical perspective, but rather with a new variety of

${ }^{27}$ I am grateful to Julia Beck for suggesting the use of this sign to indicate this function. 
Polish in which the presence of the subject RP is not restricted to focus. Interlingual identifications such as these are undoubtedly the driving force behind the evolution of convergence areas, discussed in section 2 .

\section{Extending the diasystematic approach - register-variation}

As noted in section 1, structural variation is by no means restricted to bilinguals: Just as code-switching is typical of the spontaneous, informal speech of bilinguals, monolinguals also regularly make use of different structures according to register. Consider the following two examples from English:

(20) She and I were going to go.

(21) Me 'n' her were gonna go.

Although only sentence (20) is correct in terms of prescriptive Standard American English and structures such as that in (21) are avoided by many speakers, (21) is nonetheless perfectly well-formed for many speakers in a number of contexts, e. g., a spontaneous, relaxed, face-to-face conversation between close friends. If we were to write a descriptive grammar of American English, excluding (to the extent possible) all prescriptive tendencies, it is clear that we would have to include a grammatical rule to account for the different forms of the subject in both of these utterances, not just that in $(20) .^{28}$

The form of the subject in (20) can easily be determined by rule (4.25a) for the nominative from Van Valin (2005: 108), given here as (22a).

(22) Case assignment rules for accusative constructions:

a. Assign nominative case to the highest ranking macrorole argument (in terms of [the privileged syntactic argument selection hierarchy: arg. of DO > 1st arg. of do'> 1st arg. of pred' (x, y) > 2nd arg. of pred']). ${ }^{29}$

b. Assign accusative case to the other macrorole argument.

${ }^{28}$ In the following, for the sake of presentation we will only deal with the different forms of the subject of these two sentences, ignoring all other differences between them, such as the phonologcal difference e. g. between [ænd] vs. [en]/[n]] for <and $>$ or [gowint ${ }^{\mathrm{h}} \mathrm{u}$ ] vs. $[\mathrm{g} \Lambda \mathrm{nn} \Lambda$ ] for $<$ going to $>$, indicated in examples (20) and (21) by differences in spelling.

${ }^{29}$ The privileged syntactic argument selection hierarchy which has been inserted here is from Van Valin (2005: 100). 
However, (22) will not predict the form found in (21), although (21) is in a very real sense the same language as (20). Here, a rule differentiating between subject RP's consisting of simple vs. conjoined pronominal forms is required. RP's consisting of a single pronominal will then appear in the "nominative", such as I was gonna go, in contrast to RP's consisting of two units, at least one of which is a pronominal, as in Me ' $n$ ' her in (21) or Me ' $n$ ' Sean in Me ' $n$ ' Sean used to live next door to each other, which appear in the oblique or "accusative" case.

The rule to derive the structure in (21) will of course only apply in certain contexts or registers, which we at first glance might wish to term "informal", in contrast to rule (22) above, which might be said to apply in more "formal" contexts. Viewed in this manner, we are primarily dealing here with two distinct but closely related - varieties of English, both with their own grammar and lexicon, and one solution to the apparent contradiction in subject-formation rules for English and other such differences might be to write two different grammars, one of "formal English" and one of "informal English", or perhaps "written English" and "spoken English", respectively.

This is, however, not a viable option since such a simple binary distinction (informal / formal or written / spoken) is far too simplistic to account for the full range of register variation found in English (or any other language). For example, there are many "informal" situations where the prescriptive rule might nevertheless be expected, e. g., a meeting at work among colleagues who for the most part know each other quite well but perhaps are still interested in maintaining an image of "correctness", or children who use the non-prescriptive construction with their friends but whose parents do not approve of its use, so that the children try to use the prescriptive construction at home with their parents, etc. Needless to say, it is not possible - nor desirable - to construct a separate grammar for each context.

Similar examples can easily be found in other languages. For example, the discussion in Sharbau (2011) strongly suggests that, while more formal registers of Russian obligatorily make use of a precore slot at least for constituent questions ( $w h$-questions), this is not the case with less formal, spoken Russian, where the interrogative may also appear core-internally. Here again we have different "grammars" for different versions of the "same language".

Weinreich (1954) speaks of "standardized" and "non-standardized" or "folk" languages. For example, with respect to the question of "dialect", he notes that, 
while it is easy to distinguish between standardized languages, where "it is part of the process of standardization itself to affirm the identity of a language", this is not as true of non-standardized languages (to which we can add non-prescriptive and other register-dependent forms), where "it is NOT a part of the experience of its speakers, and is much more difficult to supply." (Weinreich, 1954: 396, emphasis in original) In fact, as he argues, it is not even possible to divide the "continuum of folk language" on the basis of purely structural criteria, as the criteria will not always point to the same division, so that some criteria and bundles of criteria will necessarily be (arbitrarily) taken as the primary division. ${ }^{30}$

There are two aspects here which must be dealt with separately - the structures involved and the contexts in which they (may) occur. With respect to the contexts in which the various structures (may) occur, there are a large number of factors which may contribute to the choice of one structure over another. For example, Biber (1988: 30-33) lists eight major components of the speech situation, most of which have a number of sub-components. These are given in Table 1 (adapted from Biber 1988: 30-31). Although Table 1 presents a quite detailed list of factors which contribute to the identification of a "context", this list is not likely to be exhaustive.

With respect to structure, it is clear that some structures are more complex than others, e. g. subordinated structures as opposed to adjoined structures, informationally dense structures (e. g., NPs with attributive adjectives and relative clauses) as opposed to structures consisting of one contentive or "lexical" morpheme, etc. In a number of recent studies, Maas (e. g. 2006, 2008, 2010) refers to these two structural extremes by the terms "orate" and "literate", which should not be confused with "spoken" and "written" - e.g., it is possible to have literate structures in spoken language (e.g., a formal speech) and orate structures in written language (e.g., chat-rooms).

In recent years, typologists have made considerable progress in the field of register-based, language-internal variation, and it has become increasingly apparent that many of the descriptive devices used for literate structures cannot simply be applied to orate structures, especially highly orate structures found e.g. in spontaneous, relaxed face-to-face conversations. ${ }^{31}$ Above all, the traditional no-

30 "It is evident that no unambiguous concept of dialect could emerge even from this optimistic methodology any more than a society can be exhaustively and uniquely divided into 'groups'." (Weinreich 1954: 397)

${ }^{31}$ For reasons of space, it is not possible to provide a detailed discussion of the many advances which have been made in the field of language structure and register variation in recent years. For an 


\begin{tabular}{|c|c|c|}
\hline I & \multicolumn{2}{|c|}{ Participant roles and characteristics } \\
\hline & A. & Communicative roles of participants \\
\hline & & 1. addressor(s) \\
\hline & & 2. addressee(s) \\
\hline & & 3. audience \\
\hline & B. & Personal characteristics \\
\hline & & 1. stable: personality, interests, beliefs, etc. \\
\hline & & 2. temporary: mood, emotions, etc. \\
\hline & C. & Group characteristics \\
\hline & & 1. social class, ethnic group, gender, age, occupation, education, etc. \\
\hline II. & \multicolumn{2}{|c|}{ Relations among participants } \\
\hline & A. & Social role relations: relative social power, status, etc. \\
\hline & B. & Person relations: like, respect, etc. \\
\hline & C. & Extent of shared knowledge \\
\hline & & 1. cultural world knowledge \\
\hline & & 2. specific personal knowledge \\
\hline & D. & 'Plurality' of participants \\
\hline III. & \multicolumn{2}{|c|}{ Setting } \\
\hline & A. & Physical context \\
\hline & B. & Temporal context \\
\hline & C. & Superordinate activity type \\
\hline & D. & Extent to which space and time are shared by participants \\
\hline IV. & \multicolumn{2}{|c|}{ Topic } \\
\hline V. & \multicolumn{2}{|c|}{ Purpose } \\
\hline & A. & Conventional goals \\
\hline & B. & Personal goals \\
\hline VI. & \multicolumn{2}{|c|}{ Social evaluation } \\
\hline & A. & Evaluation of the communicative event \\
\hline & & 1. values shared by whole culture \\
\hline & & 2. values held by sub-cultures or individuals \\
\hline & B. & Speaker's attitudes towards content \\
\hline & & 1. feelings, judgements, attitudinal 'stance' \\
\hline & & 2. key: tone or manner of speech \\
\hline & & 3. degree of commitment towards the content, epistemological 'stance' \\
\hline VII. & \multicolumn{2}{|c|}{ Relations of participants to the text } \\
\hline VIII. & \multicolumn{2}{|c|}{ Channel } \\
\hline & A. & Primary channel: speech, writing, drums, signs, etc. \\
\hline & B. & Number of sub-channels available \\
\hline
\end{tabular}

Table 1: Components of the speech situation (Biber 1988: 30-31) 
tion of "sentence" has been called into question, as many (if not in fact most) utterances in informal, spontaneous speech are not grammatically well-formed sentences in the traditional sense of a predicate and its arguments and optional adjuncts (cf. e. g. Miller \& Weinert 1998). Rather, spoken language is increasingly described in terms of "intonation units", ${ }^{32}$ where the individual intonation units in spontaneous, informal speech tend to be short units consisting maximally of one new concept (Chafe 1994), which tends to be restricted to S or P function (or, in RRG terms, AI, UI, UT) (cf. Du Bois 1987, 2003), although there is considerable cross-linguistic variation with respect to whether or not arguments are overtly mentioned at all (cf., e. g., Bickel 2003). These intonation units are also often referred to structurally as "information chunks" to highlight their "non-sentential" structure. This methodology is increasingly leading to new insights in a number of areas, such as Tao's important study of the structures found in spoken Chinese (Tao 1996) as well as the importance of register variation in field research (cf. e. g. Foley 2003).

In line with most research on bilingualism from the past decades, it was argued in the previous sections that the linguistic repertoire of bilingual individuals is best viewed not as two separate "languages" but rather as context-sensitive competing forms and combinatory rules for these forms which only gradually come to be viewed as two distinct languages during the course of the bilingual's socialization. In view of the comments made above with respect to orate and literate structures, I argue that "multilectalism" can best be viewed in a similar fashion by assuming that the (mono- or multilingual) individual has a number of linguistic structures such as forms, syntactic templates and rules at his or her disposal, some of which are unmarked for context while others are only appropriate in certain contexts. For most speakers of a particular "language", the vast majority of linguistic structures will be unmarked for context, although in many diglossic situations, such as those found in much of South Asia, ${ }^{33}$ there may be a considerably higher number of context-specific lexical items, rules and syntactic templates.

overview, cf. e.g. (in alphabetical order) Biber (1988, 1995), Chafe (1994) and Maas (2006, 2008, 2010).

32 Or "IUs", not to be confused with the "information units" (IUs) of RRG!

${ }^{33}$ For an overview of diglossia in South Asia, cf. the discussion of diglossia in Shapiro \& Schiffman (1981: 164-173). 
It thus seems best to employ the same general indexing strategy to indicate contextually restricted forms, syntactic templates, etc., as was used in the previous section to mark these for distinct languages. The main difference is that a much larger portion of linguistic structures will tend not to be indexed here, as many if not most structures in a particular language will not be restricted to a particular context. Although much work is necessary for a fully adequate system of indexing, I would suggest for the time-being that structures whose use is restricted by context be indexed for those contexts for which they are appropriate, whereas contextually unmarked structures are not indexed for context.

With respect to the particular criteria, I would suggest using a subset of the criteria given above in Table 1, listing only those criteria which are deemed relevant; (23) provides an example of some of the indices which could be used. While determining the most suitable criteria will require much further research, as a first approximation we can assume this small list of variables, where each criterion could have a number of potential values. (23) makes no claims to exhaustivity with respect to the various categories, with respect to their potential values, nor does it lay any claim to universality.

(23) < ADDRESSEE > with any of a number of possible values for the following subclasses:

<PERCEIVED POWER-RELATION; AGE-RELATION; GENDER; (DIS)LIKE;

\pm SHARED GROUP STATUS; \pm FAMILIAR; EDUCATION LEVEL, . . >

$<$ TOPIC $>$ (potentially infinite number of values)

$<$ PURPOSE $>$ (potentially infinite number of values)

$<$ ATTITUDINAL STANCE OF SPEAKER>

$<$ EXPECTED ATTITUDINAL STANCE OF INTERLOCUTOR $>$

$<$ CHANNEL $>$ (e. g., written, spoken, ... )

For example, with the prescriptive and colloquial forms of composite subjects discussed above for examples (20) and (21), a possible indexation of the prescriptive form for a young speaker who has observed that the prescriptive construction is to be used with teachers and parents - or perhaps with older persons in general could have the form <ADDRESSEE: OLDER > to indicate that this rule is used with older addressees in general. On the other hand, an upwardly striving member of the middle class could have a very different view of the prescriptively correct con- 
struction in (20), e. g. either as the unmarked construction or perhaps as a marked construction to be used with addressees of a particular type, e. g. <ADDRESSEE: EDUCATED; +SHARED GROUP STATUS>. Again, we stress that the determination of the most appropriate criteria and their possible values awaits further study, although it would seem that the present approach provides a good basis for dealing with language-internal and -external variation by means of the same basic approach, while also allowing us to account for speaker-specific variation. ${ }^{34}$

\section{Summary and outlook}

Although a large portion of the world's population - over half by some estimates - is multilingual, most formal linguistic theories are either explicitly or at least implicitly modelled on monolingual language use, forcing us to view bilinguals as "two monolinguals in one person" (cf. Grosjean 1989), despite all evidence to the contrary. Even most theoretical accounts of bilingual speech assume that the speaker is speaking either one language or the other at any one moment, and few make any explicit mention of register. We have tried to rectify this situation here by developing a theoretical model of mono- and bilingual language variation which is compatible with the general tenets of Role and Reference Grammar (RRG), a typologically informed, monostratic linguistic theory which strives to make as few assumptions as possible with respect to "universal" structures, assuming only those which are necessary for the description of all languages.

The underlying idea in this model is that "languages" are not discrete systems which are stored separately in the brain. Rather, following Matras (2009), languages are viewed here as patterns of context-bound structures which are associated with a range of social activities (e.g., interlocutors, topics, etc.) and which bilingual speakers in the course of their linguistic socialisation learn to view as distinct "languages". Indeed, the very fact that bilingual speakers can and regularly do employ structures from different languages in the course of their daily routines forces us to recognize the fact that linguistic structures from both languages are simultaneously accessed and combined to form bilingual utterances,

${ }^{34}$ In fact, as Balthasar Bickel (personal communication) suggests, even this model is overly simplistic, as multiple factors are at work in any situation, so that we are dealing with statistical probability here, not with absolute predictability. In this case, the individual criteria can be combined with one another and can be weighted differently for individual speakers and situations, which can then serve as the basis for further analysis. Clearly, much work remains to be done in this area. 
thus the view of languages as discrete systems cannot be upheld and must be replaced by a more dynamic model.

Following Höder's (2012) recent approach to bilingual speech within a Construction Grammar framework, the present study makes use of Weinreich's (1954) notion of "diasystem" to account for related structures in different languages and dialects, a notion which relies heavily on Weinreich's (1953: 7-8) notion of "interlingual identification", in which components from two different linguistic systems are viewed as equivalent due to perceived similarities: Although interlingual equivalents from two different linguistic systems will, by definition, share a number of common characteristics, their identification is not a straightforward matter but rather a question of what the speakers themselves view as equivalent (cf. Höder 2012: 245), which can only be determined through the analysis of reallanguage data.

As RRG essentially views languages as networks of structures for various levels of description and rules for linking one level with another (e. g. semantics and syntax), it is especially well-equipped to handle bilingual speech as this is understood here: Both languages are viewed as networks of context-bound structures, to both of which the bilingual speaker and interlocutor have access and from both of which the speaker may freely combine structures, to the extent that s/he views these as interlingual equivalents. These structures may be indexed as belonging to one language or the other, but they may also be unspecified for language, as they belong to both linguistic repertoires. Thus, the only real innovation to mainstream RRG being proposed here is that these two networks are not viewed as entirely discrete systems but rather as "permeable" or "penetrable", as they allow the inclusion of structures from other repertoires, to the extent that these are felt by speakers to "fit". To my knowledge, this violates none of the basic principles of RRG and can easily be incorporated into the theory in its present form.

This view of language has the additional benefit that it not only allows us to describe bilingual speech, it can also be extended to include dialectal variation as well as register variation within a particular language, e. g. the different forms of the subject in sentences such as She and I were going to go vs. Me ' $n$ ' her were gonna go. Just as linguistic structures can be indexed for "language", structures within one of these languages can also be indexed as being (preferentially) ${ }^{35}$ re-

${ }^{35}$ Cf. note 34 . 
stricted to specific discourse constellations. E. g., the sentence She and I were going to go could be indexed by some speakers (e. g., young children) as restricted to discourse situations involving older speakers, and Me ' $n$ ' her were gonna go would then be unmarked, while for other speakers (e. g., upper middle class adults) the first construction would be unmarked while the second would be indexed as preferentially informal, etc. As code-switching with bilinguals is similar in many ways to register variation with monolinguals (and bilinguals as well!), this allows us a uniform approach to two different but related phenomena.

As research into the area of register variation is increasingly showing, spontaneous informal speech, to which bilingual utterances generally belong, cannot always be accounted for by the categories of traditional grammatical description, above all by categories such as the "sentence" as this has traditionally been understood - i. e., a predicate with its arguments and perhaps also one or more adjuncts. Although we of course do find sentential structures in spontaneous spoken language, we also regularly find structures, often referred to as "information chunks", which are perfectly acceptable in the context in which they are uttered but which cannot be accounted for in terms of a grammatically acceptable "sentence”, at least not as this term is traditionally understood, such as What?! Me?! Drink beer?! Never! None of these is a "sentence" in the traditional interpretation of this term, although all four utterances are perfectly acceptable in a number of (informal) situations, and any recording of naturally occurring, spontaneous spoken language will yield many further, similarly "ungrammatical" examples from a prescriptive perspective.

Not only do utterances such as these not disrupt the flow of discourse, they tend to not be viewed as "incorrect" or to even be noticed during the discourse itself. As such, a descriptively adequate grammatical theory must find a way of accounting for utterances such as these, in addition to the typical sentential structures found in most formal linguistic studies, which even today still show a strong predilection for sentences which have either been invented by the researcher or at least edited somewhat to make them "grammatical". There are probably few other formal grammatical theories which are as well equipped as RRG to undertake this challenge, and it is hoped here that the present model will prove to be at least a small first step in this direction. 


\section{Abbreviations used}

1, 2, 3 - first / second /

third persons

ADESS - adessive

AUX - auxiliary verb

COMPAR - comparative

COP - copula

DAT - dative

$\mathrm{F}$ - feminine

INF - infinitive
INTERJ - interjection PURP - purposive

LOC - locative

$\mathrm{M}$ - masculine

NEG - negative

NOM - nominative

NPST - nonpast

PERF - perfect

PRS - present

PST - past
$\mathrm{Q}$ - interrogative marker

PTCP - participle

REFL - reflexive

SG - singular

STV - stem vowel

SUBJ - subjunctive

\section{References}

Bartnicka, B., B. Hansen, W. Klemm, V. Lehmann \& H. Satkiewicz. 2004. Grammatik des Polnischen. München: Sagner.

Bialystok, E. 2001. Bilingualism in development. Language, literacy and cognition. Cambridge: Cambridge University Press.

Biber, D. 1988. Variation across speech and writing. Cambridge: Cambridge University Press.

Biber, D. 1995. Dimensions of register variation. Cambridge: Cambridge University Press.

Bickel, B. 2003. Referential density in discourse and syntactic typology. Language 79: 708-736.

Bielec, D. 1998. Polish. An essential grammar. London / New York: Routledge.

Chafe, W. 1994. Discourse, consciousness, and time. The flow and displacement of conscious experience in speaking and writing. Chicago: Chicago University Press.

Du Bois, J. W. 1987. The discourse basis of ergativity. Language 63: 805-855.

Du Bois, J. W. 2003. Discourse and grammar. In M. Tomasello (ed.), The new psychology of language. Cognitive and functional approaches to language structure, 47-87. Mahwah, NJ / London: Erlbaum.

Ferguson, C. A. 1959. Diglossia. Word 15: 325-340.

Foley, W. A. 2003. Genre, register, and language documentation in literate and preliterate communities. In P. K. Austin (ed.), Language documentation and description 1,85-98. London: School of Oriental und African Languages. 


\section{References}

Gardner-Chloros, P. 2009. Codeswitching. Cambridge: Cambridge University Press. Grosjean, F. 1989. Neurolinguists beware! The bilingual is not two monolinguals in one person. Brain and Language 36: 3-15.

Gumperz, J. 1982. Discourse strategies. Cambridge: Cambridge University Press.

Höder, S. 2012. Multilingual constructions: a diasystematic approach to common structures. In K. Braunmüller \& C. Gabriel (eds.), Multilingual individuals and multilingual societies, 241-257. Amsterdam / Philadelphia: Benjamins.

Jarząbkowska, P. E. 2012. Pronomina in der polnischen Sprache polnischer Migranten in Deutschland. Christian-Albrechts-Universität zu Kiel, Master's thesis.

Johanson, L. 2008. Remodeling grammar. Copying, conventionalization, grammaticalization. In P. Siemund \& N. Kintana (eds.), Language contact and contact languages, 61-80. Amsterdam: Benjamins.

Kaschubat, S. 2004. Code-Switching in der Sprache der russisch-deutschen Migranten in Deutschland. University of Osnabrück, Master's thesis.

Maas, U. 2006. Der Übergang von Oralität zu Skribalität in soziolinguistischer Perspektive. In U. Ammon et al. (eds.), Soziolinguistik. Ein internationales Handbuch, Vol. 3/3, 2147-2170. Berlin: de Gruyter.

Maas, U. 2008. Sprache und Sprachen in der Migrationsgesellschaft. Osnabrück: V\&R Unipress, Universitätsverlag Osnabrück.

Maas, U. 2010. Literat und orat. Grundbegriffe der Analyse geschriebener und gesprochener Sprache. Grazer Linguistische Studien 73: 21-150.

Matras, Y. 2009. Language contact. Cambridge: Cambridge University Press.

Miller, J. \& R. Weinert. 1998. Spontaneous spoken language. Syntax and discourse. Oxford: Oxford University Press.

Muysken, P. 2000. Bilingual speech. A typology of code-mixing. Cambridge: Cambridge University Press.

Muysken, P. 2013. Language contact outcomes as the result of bilingual optimization strategies. Bilingualism: Language and Cognition 16(4): 709-730.

Myers-Scotton, C. 1993. Duelling languages: Grammatical structure in codeswitching. Oxford: Clarendon Press.

Myers-Scotton, Carol. 2002. Contact linguistics: Bilingual encounters and grammatical outcomes. Oxford: Oxford University Press.

Peterson, J. 2009. "Pseudo-Verbs" - an analysis of non-verbal (co-)predication in Maltese. In B. Comrie, R. Fabri, M. Mifsud, T. Stolz \& M. Vanhove (eds.), 
Introducing Maltese linguistics. Proceedings of the 1st international conference on Maltese linguistics, 181-204. Amsterdam / Philadelphia: John Benjamins.

Peterson, J. 2010. Language contact in Jharkhand: Linguistic convergence between Munda and Indo-Aryan in eastern-central India. Himalayan Linguistics 9(2): 56-86.

Peterson, J. 2011. Aspects of Kharia grammar - A Role and Reference Grammar (RRG) approach. In R. Singh \& Gh. Sharma (eds.), Annual Review of South Asian Languages and Linguistics, 2011, 81-124. Berlin / New York: Mouton de Gruyter.

Peterson, J. 2013. Parts of Speech in Kharia - A formal account. In J. Rijkhoff \& E. van Lier (eds.), Flexible word classes. Typological studies of underspecified parts of speech, 131-168. Oxford: Oxford University Press.

Poplack, S. 1981. Sometimes I'll start a sentence in Spanish Y TERMINO EN ESPAÑOL: Toward a typology of code-switching. Linguistics 18: 581-618.

Rodionova, E. 2001. Word order and information structure in Russian syntax. University of North Dakota, Master's thesis.

Available online: http://arts-sciences.und.edu/summer-institute-of-linguistics/ theses/_files/docs/2001-rodionova-elena.pdf

Ruhnau, A. 2011. Interpretation of the topological field model of the German clause in Role and Reference Grammar. Heinrich-Heine Universität Düsseldorf, Master's thesis.

Available online: http://linguistics.buffalo.edu/people/faculty/vanvalin/rrg/ Arne\%20Ruhnau\%20-\%20Masterthesis\%20\%28revised\%29.pdf, accessed February $2,2013$.

Shapiro, M. C. \& H. F. Schiffman. 1981. Language and society in South Asia. Delhi / Varanasi / Patna: Motilal Banarsidass.

Sharbau, I. 2011. Question formation in English and Russian: A Role and Reference Grammar analysis. Universität Osnabrück, Master's thesis.

Tao, H. 1996. Units in Mandarin conversation: Prosody, discourse, and grammar. Amsterdam / Philadelphia: Benjamins.

Van Valin, R. D., Jr. 2005. Exploring the syntax-semantics interface. Cambridge: Cambridge University Press.

Weinreich, U. 1953. Languages in contact: Findings and problems. The Hague: Mouton.

Weinreich, U. 1954. Is a structural dialectology possible? Word 10: 388-400. 


\section{References}

Weinreich, U. 1958. On the compatibility of genetic relationship and convergent development. Word 14: 374-379.

Winford, D. 2003. An introduction to contact linguistics. Malden, MA: Blackwell.

Wolf, H. 1995. Fries-Nederlandse Code-wisseling. University of Utrecht, seminar paper.

\section{Author}

John Peterson

Department of General Linguistics

University of Kiel

jpeterson@linguistik.uni-kiel.de 
